\title{
EVOLUTION AS A KALEIDOSCOPE: EXPERIENCES OF RESILIENCY AND RELEVANCY IN LETHBRIDGE, CANADA
}

\author{
P. STEIN \\ Community Planner, City of Lethbridge, Canada.
}

\begin{abstract}
In 2014, former Governor General of Canada Adrienne Clarkson gave a lecture series entitled Belonging: The Paradox of Citizenship. In her first lecture, Clarkson questions the dominant notion of evolution as an "upward staircase" producing ever-more superior versions of species and societies. She contends rather that evolution is a kaleidoscope, in which evolving subjects are constantly shifting and adapting to changing stimuli. The concept of "evolution as a kaleidoscope" can be applied to longrange community planning. This perspective suggests that community development is less about urban areas trying to be better than others and how they once were, and more about a continuous movement towards resiliency and relevancy in the face of external realities, be they economic, environmental, social or otherwise. In Lethbridge, a city in southwest Alberta, Canada, approaching a population of 100,000 , the evolutionary kaleidoscope is shifting. As the City nears this meaningful moment, it offers a unique opportunity for self-reflection, revealing a City increasingly influenced by conversations about the environment, demographics and relationships with Indigenous peoples. Resiliency and relevancy are presented as tools to help bring focus to complex, changing and often daunting external realities. This article explores resiliency, relevancy and community evolution through the City of Lethbridge's on-going long-range planning work.

Keywords: Alberta, community engagement, community planning, Lethbridge, long-range planning, resiliency, relevancy, reconciliation.
\end{abstract}

\section{INTRODUCTION}

The community planners at the City of Lethbridge will tell you-tongue firmly planted in cheek-that at precisely 9:36 am on 28 March 2018, the population of the City of Lethbridge will reach 100,000 people. Despite the significant milestone, no one suggests that this turn of the population odometer will result in a real or immediate shift in community perceptions, expectations or even municipal servicing strategies. Like most things in the world of urban development, those types of changes are gradual and are influenced by a multitude of factors, not simply population size.

However, what 100,000 does offer is an opportunity. Perhaps because of the subconsciously appealing roundness of the number, it catches people's attention and, when nudged, allows them to reflect back on what it means to live in a city that size. How does a city of 100,000 look and feel? What services does it provide? How does it consider the environment? Where do people work, live, and play? How do citizens get engaged? There is no shortage of intriguing questions that municipal staff would love to ask residents leading up to this particular moment in time to get a glimpse of what the future may hold. 
For planners, this is a rare opportunity. While the work of long-range planning is essentially ask and analyse these types of questions constantly, it is typically a frustrated process confounded by planners' struggle to relate to residents and explain the goals of their work. This may be because it is often difficult for residents to see themselves in the long timelines of such work and in the long-range plans themselves, leaving them little incentive to participate.

Beyond being presented with a unique opportunity to frame values and visioning questions, Lethbridge's planners also recognize 100,000 as a chance to reflect on prevailing ideas of community development. It is a chance to consider what it means for a city to evolve over time, and how each new emerging iteration of the city relates to the fundamental values and external realities relevant at that moment: be they economic, environment, social or otherwise.

This article explores the journey that the City of Lethbridge is currently taking to conceptualize its next iteration of future growth, as captured through its highest-order statutory plan, the Municipal Development Plan or MDP [1].

Two key concepts_-resiliency and relevancy — are presented as tools to help bring focus to complex, changing and often daunting external realities that influence the evolution of a community. These concepts are particularly relevant in Lethbridge as it nears its key moment of reflection, and relate to three key conversations: protection of the local environment, adapting to changing demographics, and building relationships with Indigenous peoples.

Before discussing the City's current long-range planning work, it is important to first discuss the meaning of "community evolution," introduce the City of Lethbridge, and shed light on the key external realities the City currently faces.

\section{AN ALTERNATIVE VERSION OF COMMUNITY EVOLUTION}

In 2014, former Governor General of Canada Adrienne Clarkson gave a series of lectures entitled Belonging: The Paradox of Citizenship [2]. In her first lecture, "The Circle Widens", Clarkson questions the predominant notion that evolution is an "upward staircase" producing ever-more advanced or superior versions of species or societies. (In this article, I expand the idea of evolution to also include communities as another type of evolving subject.)

In this prevailing evolutionary paradigm, the evolving subject changes over time to become better than it once was. Evolution in this sense is seen as both the means and the end: to become better for the sake of being better. When we look forward up the staircase we see our better selves, and when we glance back, we see how far we have progressed. From this perspective, as cities grow and develop, the pursuit of superiority reigns supreme. That perspective often translates into inter-municipal competition and unrelenting boosterism.

Immediately after Clarkson suggests this version of evolution, she refutes it. She contends rather that evolution is more accurately seen as a kaleidoscope, quoting A General Theory of Love, in which the "shapes and varieties of species are constantly shifting" (p. 22, [2]). In this alternate reading, species or in our case communities change in relation to something else, often outside pressures or stimuli, and not just for their own intrinsic betterment. The stimuli influence how the kaleidoscope turns and how the resulting image (the community) emerges.

Thinking about community evolution in this way links us with other concepts such as resiliency and relevancy: resiliency is defined by the Gaia Foundation [3] as "...the capacity to mitigate (diminish impacts) or adapt (respond to change)", and relevancy is defined by the Oxford Dictionary [4] as "The quality or state of being closely connected or appropriate". 


\subsection{Resiliency and relevancy}

Before resiliency and relevancy are achieved, a community must first understand its place within larger processes (environmental, social, economic, etc.), and have an acute awareness of what may lay on the horizon. A community cannot, as the Gaia Foundation suggests, mitigate (diminish) or adapt (remain flexible) to the impacts of incoming pressures if there were unanticipated, or at the very least, if once experienced, there is no way of knowing what the effects might be.

From the perspective of resiliency, while it may be impossible for a community to predict when an extreme weather event may come, a state of resiliency implies knowing the most likely types of events, planning for their occurrence, and building mitigating and adaptive properties (including attitudes) into the structures and systems that will face the greatest of the events' forces.

From the perspective of relevancy, a relevant community knows the impacts of demographic changes over time, is familiar with its demographic profile, and is aware of the underlying values, needs and challenges of each constituent group (the elderly, new immigrants, Indigenous peoples, youth, etc.). In this example, relevancy also implies that a community has taken steps towards reflecting its diversity in the way it engages and interacts with residents. For example, does the community translate its website or program materials into the languages most widely spoken in the community? Is the diversity of the community reflected in the administrative staff, who greet residents when they show up at City Hall?

With these concepts in mind, it is my contention that communities capable of remaining resilient and relevant in the face of new outward pressures can thrive, while those that cannot, face potential economic and infrastructural decline, social fracturing and political irrelevancy.

If we support the contention that evolution is a kaleidoscope, we begin to see community development and growth in a new way. Evolution is less about trying to be better than before and better than others, and more about constantly shifting to be better suited and more responsive to the ever-changing world. From there, and as current external realities start to enter our consciousness, we begin to challenge prevailing paradigms such as "growth pays for growth", (the idea that infrastructure and servicing requirements of endless urban expansion are financially sustained through the added tax revenue of the growth itself), how we relate to the environment, and even the ways in which we speak to our residents. In Canada and North America, some noticeable external realities include:

- Massive municipal infrastructure deficits [5], leading some American municipalities to declare bankruptcy [6];

- Fragmented landscapes/land-use competition [7];

- Growing cultural diversity in communities [8];

- Changing global and local climates; and

- Stronger Indigenous voices in conversations about resource development and conservation.

Like many places in North America, Lethbridge is not alone in observing change on the horizon. Many communities across Canada and the world have identified that the world is a different place than it was after World War II or even a few years ago, and that a new set of realities are driving future planning and decision making. However, every jurisdiction has a 
unique history, and is guided by local values that, along with a similarly unique set of external stimuli, help to shape its on-going evolution-as has always been the case.

Lethbridge's community planners are approaching their current work to update the City's guiding long-range plan (the MDP) from the second "evolutionary perspective:" that collaboration, openness to new perspectives, and a willingness to understanding the realities around them can do nothing but lead to better, more informed outcomes and a more resilient, relevant community.

\section{CITY OF LETHBRIDGE, A BRIEF HISTORY}

Lethbridge is located in southwestern Alberta, at the confluence of the St. Mary and Oldman Rivers, within the South Saskatchewan River Watershed. The City is approximately $200 \mathrm{~km}$ south of Calgary, the province's largest City, and $100 \mathrm{~km}$ north of the United States border. Lethbridge is a regional economic, service and educational hub in southwest Alberta, and has a trade area of over 275,000 people stretching west into the neighbouring province of British Columbia and south into the US [9]. The City of Lethbridge is almost entirely surrounded by the Lethbridge County, a municipality economically and culturally linked to agriculture. The City also shares a meandering 10-km border with the Kainai First Nation.

The pre-contact history of the region stretches back millennia, what the Indigenous Blackfoot peoples describe as since time immemorial. The traditional territory of the Blackfoot stretches many hundreds of thousands of square kilometers across the Great Plains of North America, including into what are now the provinces of Alberta and Saskatchewan, and the state of Montana.

The place where we find Lethbridge, located at the confluence of two rivers and around a productive riverine ecosystem, would have provided resources and refuge for the Blackfoot both seasonally and year-round as they travelled and occupied all corners of their extensive traditional territory.

Shortly after Canada's confederation in 1867, Indigenous peoples were forced onto Reserves where they were confined in relative physical and ideological isolation from the rest of society. It was in this isolation that Indigenous peoples experienced a massive statesponsored project of assimilation, abuse and neglect [10]. Indigenous peoples today, including in Lethbridge, are working to regain their voice and place in society.

The City of Lethbridge was founded in 1906, and the history of this City largely reflects a changing regional economy: from the fur trade, to the arrival of the coal industry, and later irrigation agriculture and agri-processing. In more recent years, the local economy has been strongly influenced by public sector work, including the City's two post-secondary institutions, a regional hospital, federal agricultural research and large municipal and provincial workforces. In 2011, nearly 30\% of employment in the City was in health care and social assistance, educational services and public administration [11].

\section{CHANGING REALITIES}

This article touches on three issues that currently, and will increasingly dominate conversations about Lethbridge's future-protecting the environment, adapting to changing demographics, and relationship-building with Indigenous peoples-and how they influence an on-going long-range planning project. These conversations are not unique to Lethbridge, as many municipalities in the post-industrial and post-colonial world are also experiencing them.

Alberta has an extremely fragmented landscape, challenged by multiple and competing land uses, including: urban growth, conservation, agriculture, linear infrastructure (e.g. pipe- 
lines, roadways), resources extraction (e.g. natural gas, coal, timber), and recreation. In recent years, there has been growing consensus that land-use competition is stressing the ability of natural systems to provide the ecological goods and services needed to support the region's communities and economies. Moreover, with the anticipated impacts of climate change and growing knowledge of cumulative impacts, there is uncertainty about what the future holds for stressed ecosystems species and landscapes, and the people relying on them.

Albertan communities, like many across Canada, are also experiencing the results of growing reliance on immigration to fill jobs left by an aging workforce. This is producing urban areas that are ever more ethnically diverse. This is especially the case when we examine the changing set of origin countries that dominate immigration patterns in Canada: first led by countries in Western and Eastern Europe, and now by Asia, and to a lesser extent Africa and Latin America [8]. For example, Lethbridge has the largest Bhutanese community in Canada [12], and Spanish is now the most widely spoken home language after English [13]. Another demographic change on the horizon is a new generation of homebuyers and renters (Generations $\mathrm{Y}$ and $\mathrm{Z}$ ), and the values and economic realities that will drive what types of neighbourhoods and homes they want to live in.

Interestingly, at the same time as our cities look and feel more global, the presence and importance of Indigenous peoples has grown in our local consciousness. In recent years, this has been the result of social movements such as Idle No More, the findings of a national Truth and Reconciliation Commission [10], and calls for a National Inquiry into Missing and Murdered Indigenous Women and Girls. An awareness of Indigenous values and issues is especially important in urban areas as they are home to the majority of Indigenous people in Canada [14].

Again, while these topics are not necessarily new or unique to Lethbridge or even Alberta, in recent years they have emerged with a new intensity, reflected in both regional legislation, and as discussed below, community planning.

\subsection{Changing realities reflected in legislation}

The City of Lethbridge is faced with new legislative direction in the form of a regional landuse plan [15]. The South Saskatchewan Regional Plan (SSRP), adopted by the Province of Alberta in 2014, embodies many of the external stimuli discussed above and provides strategic and legislative direction to municipalities to ensure their consideration in planning and decision making.

The SSRP emerges from the need to balance multiple, competing and often seemingly incompatible land uses (e.g. resource extraction, urban growth, agriculture, tourism, conservation) in a watershed that is home to more than two million people, is governed by a patchwork of 84 rural and urban municipalities and First Nations, and which faces stressed landscapes and ecosystems [7, 15].

In many ways, the SSRP supports the notion that economic growth is only possible when ecosystems are intact and healthy and when resources and growth are managed sustainably. This, in contrast to what I would argue has historically been the dominant paradigm in many communities in Alberta: that resources exist to be extracted, and the "environment" is just the thing that gets in the way or is the place you go to recreate on the weekend.

The SSRP also pushes planners and decision makers to consider the changing needs of their communities in terms of housing, recreation and municipal services. As previously mentioned, the changing demographic realities of the region's communities include: an aging population; 
the rise of Generations $\mathrm{Y}$ and $\mathrm{Z}$ as the next wave of property owners and renters [16-18]; and growing ethnic diversity. As well in Lethbridge, poverty and socio-economic equality are also important as the City has among the highest rates of child poverty in the Province [19].

Finally, the SSRP encourages greater dialogue between Indigenous and non-Indigenous planners and decision makers. This follows a similar shift in Canada towards greater collaboration between industry, government and Indigenous communities. In fact a growing number of cities have recently begun to reimagine their relationship and responsibility to Indigenous residents and First Nation neighbours (cities like Calgary, Edmonton, Ottawa and Vancouver).

It is largely from these perspectives, and the broader realization that all residents within the watershed share a finite landscape with limited resources, and the impacts of land use tend to flow across the landscape irrespective of political boundaries that a profound realization emerges: we are all in this together, so why haven't we been working together?

Starting in 2014 with the adoption of the SSRP, Lethbridge's community planners have been trying to understand the implications of these and other external stimuli. For example, what does it mean to balance urban growth with the protection of environmental resources? Similarly, what is the most appropriate way for the City of Lethbridge to engage with Indigenous peoples?

At a higher level, these external realities have challenged Lethbridge's community planners to think about how their work contributes to a creating a resilient and relevant community in the face of external stimuli.

\section{MUNICIPAL DEVELOPMENT PLAN UPDATE}

All Alberta municipalities with a population greater than 3,500 people are required to prepare a Municipal Development Plan (MDP). MDPs are the highest order statutory plan that municipalities prepare (along with Inter-municipal Development Plans, which coordinate the interface of adjacent municipalities). MDPs are intended to set the legislative goalposts for a community, indicating the values and vision through which community growth and development will occur in the future (in Lethbridge, the MDP sets forth a 40-year vision).

At a minimum, MDPs contain language about future growth and the provision of municipal infrastructure and services. They also may speak to the preservation of environmental and historic resources and resident quality of life. All lower order municipal plans, policies and bylaws are then required to be in compliance and ultimately support the values and vision of the MDP. In the same way, with the adoption of the SSRP, all municipalities in the region are required to ensure their MDPs contribute to regional outcomes; and they must do so by 2019.

To begin the work of incorporating the outcomes of the SSRP, in 2015 Lethbridge initiated a four-year process to update its MDP. The update will be completed by mid-2019, and roughly aligns with the City's normal 10-year MDP update cycle (the current MDP was adopted in 2010). This will be the first MDP completed under the SSRP, and as such will be the vehicle used to demonstrate compliance with its outcomes. The next MDP will also be the first completed after surpassing a population of 100,000 - that significant moment of reflection.

This MDP update is different than previous updates. This time, rather than strictly being about reflecting community values in broad policy, MDP policy recommendations (they are only recommendations until ratified by Council) will be informed by a comprehensive collection of baseline data related to: 
- Historical patterns of growth and anticipated demographic trends;

- Environmental resources (e.g. wetlands, riparian areas, wildlife corridors, species at risk, air and water quality) and pressures like climate change;

- Historic resources (including for the first time both First Nation and post-settlement resources) and the concept of "reconciliation" [10]; and,

- Up and downstream implications of these patterns, resources and pressures, including on neighbouring municipalities and First Nations.

Data gathered in each area will inform resident, stakeholder and ultimately political conversations about the required actions (i.e. MDP policies) needed to reach desired local and regional outcomes. So how does this work relate back to resiliency and relevancy?

As mentioned earlier, the foundation for resiliency is knowing what trends, issues and pressures may lie on the horizon, anticipating local impacts, and creating systems, structures and attitudes capable of mitigating risk and adapting. Relevancy comes from doing that work in a way that makes sense locally.

\subsection{Planning for resiliency}

The community planning team is fostering resiliency in three ways:

\subsubsection{Situate project work within external realities}

Understanding how a community fits into larger external realities begins with knowing how the world is changing. For example, an awareness and appreciation for demographic trends, and environmental and social changes can help a community more adequately plan for the future. Because community planning is a long-term, iterative and political process, it is important to constantly have conversations about external realities in a variety of contexts.

The project team has done this by framing data collection (in-house and through consultants) and project information (e.g. press releases, presentations) with larger realities in mind (such as the aforementioned social, economic and environmental realities). The idea is that this helps individuals working both inside and outside the project to identify and gain a sense of comfort with external realities that may at first seem too daunting or abstract.

For example, over the course of the project, the case for building relationships with Indigenous peoples has been examined in different ways (e.g. in relation to social movements, court cases and provincial legislation). Offering multiple entry points into a larger conversation about why relationship building with Indigenous peoples is so important, provides various opportunities to connect to a topic that may at first not appear relevant or that seems overwhelming.

Feeling comfortable with external realities allows individuals to more easily see potential local impacts and how small actions can have ripple effects.

\subsubsection{Use data to drive outcomes}

To understand how external realities become local impacts, baseline data are crucial. A community cannot create resiliency in the face of, climate change for example, if there is no awareness about the state of local ecosystems, biodiversity, and air and water quality etc. Once data are collected, systemic, cross-discipline thinking is needed to see how the external realities may play out. 
One of the first steps in the MDP update was to identify key pieces of information that would be needed to support the future creation of policy targets. This work was done in collaboration with a multi-disciplinary group of City staff. Data mapping in this way has helped bring in new perspectives and has the added benefit of helping to identify which departments have access to what data.

The belief is that baseline data will ensure project outcomes are grounded in objective, ground-truthed reality. As the intention of the project team is to ultimately turn data and objectives into targets in key outcome areas (e.g. density, urban footprint, air quality etc.), the baseline data act as a snapshot in time against which to measure progress (resiliency) after the MDP is adopted. Indeed a key aspect of resiliency is being able to monitor change over time and ensure the community's response is adequate and can be sustained.

\subsubsection{Build partnerships between staff}

One of the ways the project team is creating resiliency in its structures, systems and attitudes is by ensuring that there is a cross-discipline support team assisting with data collection and analysis. The project team takes the perspective that when information is shared beyond one or two departments, and when analysis is a collaborative exercise, buy-in for future action comes easier. As an example, the environmental baseline data gathering work has a support team representing 15 departments, including Planning, Parks, Transportation, Transit, Water and Wastewater, Waste and Recycling, Communications, and Community Social Development. The support team enhances the project by brining technical expertise, data and analysis, and connections to department-specific planning.

Moreover, the project team has made a concerted effort to bring together staff at the beginning of their careers (although not to the detriment of gathering key institutional knowledge) to ensure that the "witnesses" to data gathering and analysis are able to shepherd that information along for many years to come.

The partnerships created between staff support resiliency because they result in greater consensus and support for the work needed to actually create the resilient structures and systems.

\subsection{Planning for relevancy}

The community planning team is creating relevancy in the three ways:

\subsubsection{Create the opportunity for local values to inform outcomes}

A theme that resonates throughout the MDP update is the idea that while baseline data collection is an objective process, the point at which data is then used to create resiliency, it becomes more subjective.

What this means is that ultimately local values need to drive whatever action is taken in response to the external realities present in the community. For example, while we may at a general level understand that more and more young people want to live in dense, centrally located, vibrant neighbourhoods [18], it is yet to be seen if and how this resonates locally. The definitions of "density", "centrally located", and "vibrant neighbourhood" are likely different in Lethbridge than they are in the other North American cities where this trend has been documented.

The project team manages this by bringing a diverse set of residents and stakeholders together to inform data collection and analysis. Infusing diverse agenda and values helps to 
ensure that the data are contemplated and interpreted in a way that is locally appropriate and representative.

\subsubsection{Bring new voices to the table}

Building on the last point, the stakeholders who are brought together to provide input signals to the broader public which community voices are valued and which are not. As our communities change over time and demand greater transparency, we need to actively seek and value the input of new voices.

The project team has sought to balance the need to bring together stakeholder groups with specific expertise or knowledge, or who may be directly impacted by MDP updates, against the need to have a varied group of generalists.

For example, when gathering data about future residential housing trends, it is natural to bring together developers, builders, real estate professionals and housing agencies. Seeing this as a minimum level of engagement, the project team has additionally and actively soughtout community resident participation from all geographic areas of the City, different age groups (youth and seniors), and groups working specifically on Indigenous and immigrant housing.

The symbolism of having often-marginalized groups at the table signals a shift in thinking, but also leads to more interesting and relevant outcomes: the youth and seniors learn from each other, as do the for-profit and non-profit sector representatives, and non-profits working with Indigenous or immigrant clients can create relationships with industry and each other. All of this leads to more well-informed results, and helps to reassure the ultimate decision makers that outcomes are driven by extensive and meaningful engagement.

\subsubsection{Change the conversation}

While the first two points speak to how to engage targeted and new voices, it is important to not neglect the larger public. However, it is often a challenge for planners to capture the interest of residents. In Lethbridge, this is often because planners have a hard time relating their long-range visions to individual residents, and because residents have a hard time seeing themselves in the outcomes of long-range planning. So why not change the conversation?

The project team is changing the conversation in two ways. First, they are flipping typical MDP engagement on its head. MDP engagement usually involves hosting forums to bring residents and stakeholders together to contribute directly to an MDP vision and policies. In Lethbridge, participation at these events is relatively low, and residents who do attend, tend to be those who always do. Getting a diversity of perspectives then becomes quite difficult. Again, if we cannot explain the goals of long-range planning in the first place, we cannot expect residents to be motivated to show-up and share their voices.

However, what people do turn out for are projects and initiatives that speak to their personal interests or that tangibly impact their daily lives. When the City is twinning a road, building a leisure centre or planning bike lanes in a neighbourhood, local residents take an interest. The project team has therefore begun conducting MDP engagement at each of these and other discrete events. In that way, the MDP begins to compile resident values and concerns about many different topics at the very moment that residents are interested in speaking about them. The MDP then becomes the common thread that links together each distinct project into a larger exercise of community evolution and gets people to start stretching beyond themselves to see larger City outcomes as connected. 
Even still, it is hard to really appreciate the role of an MDP as a tool to guide future planning and decision making. Instead of even mentioning the MDP, the project team is instead taking advantage of the significant 100,000 population milestone. This is the second way they are changing the conversation. It seems that when conversations about policy are removed, and engagement focuses on what it means to be a City of 100,000, and what the future holds for Lethbridge, people have an easier time relating (and stretching). Residents get to imagine life 20 years from now when the City has 30,000 more people: where they will live, where their kids will live, where they will work, and how they will get around.

\section{CONCLUSION}

While the formal work of Lethbridge's community planners to update the MDP is just beginning, they have spent a great deal of time thinking about the context of their work, and their role in supporting the City's evolution. As Clarkson [2] suggests, evolving subjects are constantly shifting and adapting to changing stimuli. Evolution is therefore more about being resilient to change (flexible and adaptable) and remaining relevant (connected to local realities).

High-level visioning documents such as MDPs are intended to set goalposts for planners and decision makers. They also provide clarity to residents, stakeholders and neighbours so that they can see how the community is evolving.

The process of supporting community evolution involves an awareness of what may lie on the horizon, how incoming external stimuli might impact local systems, structures and attitudes, and ensuring the action taken to remain resilient to those external stimuli is relevant.

The City of Lethbridge planning team has structured their project work in such a way that ensures outcomes are grounded in the concepts of resiliency and relevancy. They do so by starting open conversations with their colleagues, residents and stakeholders about how they see the world changing, bringing together diverse perspectives to confirm and then interpret those changes, and ultimately ground-truthing or analysing objective data through the kaleidoscope of a multitude of local realities.

The belief is that this work will lead to stronger, and more resilient and relevant outcomes that truly reflect the City's next iteration, with the support of the community itself.

\section{REFERENCES}

[1] City of Lethbridge, Integrated Community Sustainability Plan / Municipal Development Plan (Bylaw 5650), 2010.

[2] Clarkson, A., Belonging: The Paradox of Citizenship, House of Anansi Press: Toronto, 2014.

[3] Gaia Foundation, available at www.gaiafoundation.org/climate-change-resilience

[4] Oxford Dictionary, available at www.oxforddictionaries.com/us/definition/american english/relevance?q=Relevancy

[5] Mirza, S., Danger Ahead: The Coming Collapse of Canada's Municipal Infrastructure, Federation of Canadian Municipalities: Ottawa, 2007.

[6] NewsHour Productions, Which American Municipalities Have Filed for Bankruptcy? February 8, 2014.

[7] Government of Alberta, Land-use Framework, Queen's Printer, 2008.

[8] Department of Justice, Cultural Diversity in Canada: The Social Construction of Racial Difference, 2015. available at www.justice.gc.ca/eng/rp-pr/csj-sjc/jsp-sjp/rp02_8dr02_8/p3.html 
[9] Economic Development Lethbridge, available at www.chooselethbridge.ca/business/ trading_area.php

[10] Truth and Reconciliation Commission of Canada, Honouring the Truth, Reconciling for the Future: Summary of the Final Report of the Truth and Reconciliation Commission of Canada, Truth and Reconciliation Commission of Canada: Winnipeg, Canada, 2015.

[11] Statistics Canada, National Household Survey, 2011.

[12] Global News, Lethbridge Home to the Largest Bhutanese Community in Canada, 13 May 2014.

[13] Statistics Canada, Lethbridge, Alberta Census Profile: 2011 Census, 2011.

[14] Indigenous and Northern Affairs Canada, Fact Sheet-Urban Aboriginal Population in Canada, 2010. available at www.aadnc-aandc.gc.ca/eng/1100100014298/ 1100100014302

[15] Government of Alberta, South Saskatchewan Regional Plan: 2014-2024, Queen's Printer 2014.

[16] Alberta Senior and Community Supports, Demographic Planning Commission Findings Report, 2008.

[17] Statistics Canada, 2011 National Household Survey: Homeownership and Shelter Costs in Canada, 2013.

[18] Lackman, L.M. \& Brett, D. L., Gen Y and Housing: What They Want and Where They Want It, Urban Land Institute: Washington, 2015.

[19] Vibrant Lethbridge, Understanding the Impacts of and Finding Community Solutions to Poverty in Lethbridge, 2015. 